\title{
New media in political communication: general approaches
}

\author{
Marina A. Chekunova ${ }^{1, *}$, Victor V. Barabash ${ }^{1}$, Galina N. Trofimova ${ }^{1}$ and Galina N. Lenko ${ }^{2}$ \\ ${ }^{1}$ PFUR, Department of Mass Media, 115419, Moscow, Russia \\ ${ }^{2}$ NRU "Higher School of Economics", Department of Foreign Languages, 194100, St. Petersburg, Russia
}

\begin{abstract}
Nowadays, in transformation of the realm of political communication, a more important part is given to the so-called «new social media». Previously, political communication was seen as a process of production, dissemination and perception of political information for the purpose of achieving a consent regarding one or another political action. Additionally, communication appeared as a mechanism of one-way information exchange. Under new conditions, political communication becomes a tool of ensuring the process of preparation, making and implementing political decisions. In a modern understanding, an informational message is built by means of specific cooperation between communicants. In this regard, information sources appear as a specific base for state actions. This paper deals with old (traditional) and new social media and lists several characteristics that help distinguish these media. It also shows how authorities and representatives of political opposition can use social media to achieve their political purposes. This article analyses not only benefits but also drawbacks in the application of new information technologies in politics, considering a problem of manipulation as a main disadvantage. It also compares the use of social networks by authorities in Russia and abroad. Because of differences in political culture, social networks are not popular with Russian authorities. However, the number of social networking users among Russian politicians is increasing year by year. Moreover, the most popular network with them is Twitter. A conclusion can be drawn that new media play an important role in creating a system of rules of conduct on the Internet and in establishing a specific culture of electronic communication between representatives of authority and society.
\end{abstract}

Nowadays, in the western political science, state governance is more often seen as a system of selforganized networks that are characterized by interdependence, resource exchange, special rules of cooperation and significant autonomy from the state [1]. At the same time J. Kooiman [2] defines state governance as «the wholeness of state and public cooperation as regards solution of different social problems and creation of possibilities»; in other words, he draws attention to interactions that are understood as a specific form of action undertaken by actors of political communication in order not only to solve problems but also to create new courses of development. Principles of interactions based on certain worldview categories and moral values are becoming more important together with the role of collaborating institutes. This is, for example, the problem of transparency of political communication in terms of agreement between governmental and non-governmental institutes.

The requirements for the efficiency of political decision-implementing process, submitted by non-state participants, have political and communicative grounds. Ideally, communicants' interests must be mutually shared. In its turn, the demand for a bigger transparency of state authorities' actions is considered as a part of society democratization process. Nowadays, the political sphere covers a wide range of cooperation: from participation in different public organizations to on-line discussions and signing on-line petitions; citizens' activity and their cooperation in the political sphere transform political communication into some sort of assessment tool of amount and quality of democracy in a society.

Information sources appear as a specific legitimized base for state actions. In a forming information society, an important role is played by both communication possibilities and resources of state and public authorities, and also particular politicians who are able to communicate effectively with different participants of the political process. These factors in particular contribute to the growth of social trust and civil involvement in the political processes; and, vice versa, the absence of civil awareness can trigger a legitimation crisis [3].

Moreover, communication potential of authorities manifests itself in an ability to raise and solve urgent political and social problems and foresee possible risks in making decisions, especially unpopular ones. A professional use of Internet resources not only

Corresponding author: chekunova@gmail.com 
contributes to the creation of an authority profile with a positive reputation but also improves the possibilities of forecast of governance processes.

Previously, political communication was seen as a process of production, dissemination and perception of political information for the purpose of achieving a consent regarding one or another political action. In addition, the meaning of a sender's message was supposed to remain almost unchanged. In other words, in the frame of linear logic, communication appeared as a mechanism of one-way information exchange. Under new conditions, political communication becomes a tool of ensuring the process of preparation, making and implementing political decisions. In a modern understanding, an informational message is built by means of specific cooperation between communicants. This involves the attempts to manage the meaning creation during political communication [4].

In this regard, state authorities who are displayed in the «World wide web» with their own information resources are forced to adapt not only to the developing and constantly changing technologies but also to the demands of main communication actors who are actively using these technologies.

Among the addressees of political communication, at the minimum, two types of «communicants» can be distinguished: recipients of political information and consumers of public services. This implies different communication technologies, strategies and problems. For example, in Russia, despite the legal and regulatory framework controlling access to information of authorities, numerous bureaucratic and administrative barriers prevent an effective search for political information. One of them is different level authorities' commitment to using universal answers to consumers' questions. It is obvious that this practice does not contribute to the growth of trust towards authorities.

Official electronic resources of government authorities use different interaction technologies with citizens and organizations (for example, virtual reception office and interactive forums). However, in Russia, the majority of potential users of information have neither the experience nor an absolute need to exercise their right for access to information.

Nevertheless, contemporary researchers are predicting a serious reorganization of communication technologies in the realm of political communication. Despite a common decline in the number of audience of evening TV news and decrease in circulation of main newspapers (which shows loss of trust towards «traditional» media-sources), the number of Internet users getting information on-line grows constantly. The relative share of political and administrative «content» of the Internet increases steadily [5]. However, as new technologies appear, relationships between actors of communication change. A growing amount of information necessitates a quick access to it and its transparency. In its turn, multidirectionality of information exchange requires the authorities to involve new actors into communication relationships.

In transformation of the realm of political communication (including the process of shaping citizens' political preferences), a more important part is given to so-called «new social media», which is a combination of on-line technologies and practices including such tools as blogs, podcasts, video- and audiohostings and social networks [6]. In particular, a more popular way of feedback available for readers is a possibility to leave comments in a dialogue format. Some blogs are used as personal dialogue diaries. Podcast, which became widespread because of iPod, appears as a distribution of digital audio- and video files with the help of the Internet to personal computers and potable media players. Over the last few years, Twitter has become one of the most widely used social networks due to technological and communicative userfriendliness.

Nowadays, the notion «new media» is used to convey different meanings, commonly identifying them with «new mass media organizations», which constricts this sphere to new forms of mass media existence. Among all variety of definitions, two common characteristics can be found (digital nature and interactivity), they juxtapose «new media» to «traditional ones» — press, analog TVand radiobroadcasting [7]. Nowadays, any person with minimal technical capabilities is able to create their own media edition in any format. However, new media appear to represent a full industry with their own target market and professionals. Nowadays, users have access to digital video, blogging, podcasting, mobile telephones, photography and wikis. In addition to these technologies, a final product can include a combination from open resources, free software etc. Examples of Internet resources of «users'» content are Wikipedia, Facebook, MySpace, YouTube and Flickr [8].

Differences between new and old media become apparent thanks to several characteristics:

firstly, impossibility to exactly present «old media» in digital equivalent as opposed to new media that is programmed;

secondly, constructing new media, by contrast to «old» ones, according to modular principle; moreover, by constructing separate fragments into one whole massive construction they preserve their independence and primary characteristics;

thirdly, possibility to automatize many operations (including modernization or creation of new sections) without direct human control;

fourthly, as the new media can be transformed, they can exist in unlimited number of versions. As for «old media», they are strictly fixed in their composition. This gives an opportunity of distinguishing content and interface and, consequently, adapting it to personal characteristics of a user. Variability can be also seen in regulating the scale and degree of specification;

fifthly, possibility of «conversion», which means converting on-line media from one format into another. Thus, traditional media converted into network-related format appear to have a double nature. On the one hand, they can be read by a person who establishes a connection between them and other objects, on the other hand, by a computer that correlates them with other media based on its relevant characteristics (format, type of files etc.) [9]. 
Moreover, a more considerable characteristic of new media is the interrelationship within the universal network where there is audio, video and electronic text, which leads to blurring the lines between interpersonal communication and mass communication. Additionally, the way information is presented also changes. Widespread in human culture, «narration» is replaced with handling databases where information is systematized according to hierarchic, objective or another principle.

As a result, the new media work faster than the old ones. They are open and not closed as the old ones, shorter and not as talkative, active and not passive. When the old media had audience, the new ones have users. While the traditional media delivered a text, the new ones deliver an «image». Finally, while the old media only allows the producer to generate content, the new ones open this opportunity to any user. At the same time, a uniting characteristic of old and new media still remains conveying a message; however, ways and forms of this conveyance are changing. New media create conditions for transporting information through different sources and reaching its target groups. That is why old and new media may not only co-exist but also interact with each other [8].

The studying of new social media practices as a way of political communication became more intense in 2004. Initially, the research in this sphere was connected with the use of social media during election campaigns [10]. In particular, foreign researchers outlined a relation between political communication in online mode and in real life. In this regard, social media contribute to intensification of citizens' political involvement by means of providing information about the political sphere or by means of the signals motivating citizens to take particular political actions [11]. New media are widely used in social projects as well. For example, electronic edition «Open Democracy» not only engages its audience in participation in on-line discussions but also aims at creating a massive discussion platform by using forums and social networks. Analysis of messages sent by representatives of the US Congress revealed that politicians use Twitter mostly for advertising their political positions and not for calling for political actions. In addition, these informational messages more often contain links to news articles about events in the world taken from popular mass media. However, on the other hand, Twitter contributes to increase of transparency in Congress activity and, consequently, to establishing new connections between Congressmen and voters [12].

On the one hand, it is obvious that Twitter and Facebook are often used by politicians to promote their political position, mobilize electorate and communicate with their voters. On the other hand, social media played an important role in mobilizing the population against existing political regimes. A perfect example of that are the events of «Arab spring». In 2011, mass protests in Egypt, Tunisia and Libya were organized with the help of social networks Twitter and Facebook. In 2012, the organizers of protest actions in Russia also used resources of social networks Vkontakte, Facebook and
Twitter. Moreover, new media (especially, Twitter and Facebook) appear to be a spy target as they contain a systematized database. However, there is an opinion that the role of social networks is obviously exaggerated. For example, it is certain that the power crisis and economic recession were the more substantial reasons for political crisis in Moldova than citizens' activity, organized with the help of new social media [13]. Nevertheless, understanding the mobilization possibilities of social networks requires constant attention to them.

It is obvious that there are differences both in popularity of social media in Russia and abroad and in a specific character of political culture. To define a proportion and a role of social networks, it is necessary to take into account a political context where they function. Having accounts in social networks is not popular with Russian politicians. According to the data of 2014, only 53 out of 85 leaders of territorial entities of the Russian Federation had their accounts in different social networks, whereas in the USA the governors of all 50 states have active accounts on Twitter. However, the number of social networking users among Russian politicians is increasing year by year. Moreover, the most popular network with them is Twitter (ITARTASS; Twitter [14, 15]). Regional leaders focus mainly on dissemination of information about events that take place in their regions, about local innovations and improvements, about forthcoming elections etc. Similar messages in social networks serve to illustrate results of a politician's activity. However, regional leaders use network possibilities to a lesser degree to communicate directly with the population.

Other kind of the communication strategy in social networks is common for representatives of political opposition. Oppositional politicians prefer messages connected with a direct communication or private messages for drawing attention to their personality and establishing a direct contact with potential supporters.

Texts for newspapers, sites and mobile phones are created with the help of different technologies according to their tasks, and they differ in tone, style and realization of communication strategies. In a fundamentally changing information environment, political actors make contacts that are unusual for them, create a new (virtual) communication style with authorities; political possibilities of citizens and institutions are transformed into real authoritative statuses, and they have impact on distribution of social values and public resources.

However, there are not only benefits but also drawbacks in the application of new information technologies in politics. Thus, in the context of a fast and lightly regulated expansion of informational space there are growing demands for users' professionalism and qualification of search and use of political information. Increase in the number of multidirectional vectors of horizontal political communicative flows leads to the division of united audience into multitude of groups interacting according to network principle. Regardless of political context and specifics of political culture, analysis of social networks reveals a series of common significant problems connected with credibility of posted 
information, especially, since in most networks (for example, Facebook and Vkontakte) user data can be hidden by personal settings. In addition, it is a known fact that the ability of users to identify misinformation is mainly defined by their degree of confidence in the message sender. However, true motives of posting a message by a network user remain unknown.

This leads to a problem of manipulation by posting knowingly false information with the purpose of influencing opinion and behavior of other users. Social networks, namely Twitter, also allow to create false accounts that can be used to distribute any unreliable information

Thus, speaking of Russian political communication, it should be noted that, apart from depending on modern information and communication technologies, it is defined by a range of factors, from the position of authorities to nature of taken decisions. In their turn, either factor defines a common strategy of political communication, from interaction to information ignoring. Given the fact that interaction among citizens and government agencies (especially, in regions) is defined by mass media, new media can be transformed into powerful information and mobilization resources of oppositional and even deconstructive elements (experience of color revolution can be given as an example). «Top-down» attempts to establish norms of interactive behavior more often lead in practice to the opposite results coming into collision with value requirements made «from below».

The development of communication processes and use of communication potential in the political sphere are defined by existing favorable conditions, including increase in qualification of authors of electronic messages and the authorities paying extra attention to the cooperation with consumers by means of electronic resources. The latter can be witnessed with the help of both the expansion of corresponding functioning sections on official sites of authorities and the increase in competence of their answers. New media can and must play an important role in creating a system of rules of conduct on the Internet and in establishing a specific culture of electronic communication between representatives of authority and society.

\section{References}

1. R.A.W. Rhodes, Political quarterly, 65, 38-51 (1994).

2. J. Kooiman, PMR, 1(1), 67-92 (1999).

3. J. Snyder, From voting to violence: democratization and nationalist conflict (W.W. Norton, New York, 2002).

4. M. Crozier, Political communication, 24(1), 1-18 (2007).

5. L. Pashigorova, Business. Society. Authority, 4 (2010).

6. L. Kaid, and C. Holtz-Bacha, Encyclopedia of political communication (UK SAGE, London 2008).

7. R. Neuman, What are new media, or digitalglobalization. Available online: URL http://smm.artox- media.ru/wiki/new-media.html

(accessed on: 17.12.2015).

8. O. Styns, and D. Van Fucht, Science Journal of VolSU, 8 (7), 98-100 (2008).

9. A. Sakoyan, New media. Boundaries of the phenomenon. Available online: URL http://polit.ru/article/2011/08/05/new_media/ (accessed on: July 2, 2015).

10. B. O’Connor, R. Balasubramanyan, B.R. Routledge and N.A. Smith, From tweets to polls: linking text sentiment to public opinion time series. In Proceedings of the International AAAI Conference on Weblogs and Social Media. Menlo Park, CA: The AAAI Press, 122129 (2010).

11. C. Vaccari, A. Valeriani, P. Barberá, R. Bonneau, J.T. Jost, J. Nagler, and J. Tucker, Rivista italiana di scienza politica, 43(3), 381-410 (2013).

12. J. Goldbeck, J. M. Grimes, A. Rogers, and J. Assoc. Inf. Sci. Technol, 61(8), 1612-1621 (2010).

13. H. Hale, The Journal of Post-Soviet Democratization, 21 (3), 481-505 (2013).

14. ITAR-TASS. Politicians in social networks. Dossier. Available online: URL http://itar-tass.com/info/1442493 (accessed on: 21.10.2015).

15. Twitter. Public data about Twitter accounts of the US governors. Available online: URL https://twitter.com/gov/lists/us-governors (accessed on: 27.02.2016). 